\title{
ALFATHESIN AND ENFLURANE: SYNERGISTIC CENTRAL NERVOUS SYSTEM EXCITATION?
}

\author{
Robert Hudson and C.T. Ethans
}

\begin{abstract}
This case report describes signs of central nervous system excitation occurring after administration of alfathesin and enflurane in doses lower than those previously associated with this type of phenomena (alfathesin 36 microlitres/kilogram, enflurane two volumes per cent). This suggests that these drugs may interact to increase the probability of seizure-like activity.
\end{abstract}

KEY WORDS: ANAESTHETICS, complications, alfathesin, enflurane; Nerves, excitation.

BOTH ALFATHESIN and enflurane are known to cause central nervous system (CNS) excitation. ${ }^{1}$ Alfathesin is more likely to cause seizure activity when large doses are given rapidly. ${ }^{2-4}$ The CNS stimulatory properties of enflurane are accentuated by respiratory alkalosis ${ }^{5.6}$ and deeper levels of anaesthesia. ${ }^{7}$ This case report describes seizure-like activity during anaesthesia with these agents in the absence of these factors.

\section{REPORT OF A CASE}

A 23 year old, 71 kilogram man was admitted for removal of a Mueller plate from his left femur. His medical history included rheumatic fever at age six manifested by rash and arthralgias without cardiac involvement or sequelae.

He had an uncomplicated anaesthetic one year previously for open reduction and fixation of his iemur following a sky-diving accident. Anaesthesia had been induced then with thiopentone, tracheal intubation aided by succinylcholine and anaesthesia was maintained with nitrous oxide, oxygen and halothane. He had several uneventful anaesthetics during childhood for correction of strabismus, tonsilectomy and appendectomy. Pre-operative assessment revealed no other medical problems. Physical examination disclosed no abnormalities.

Anaesthesia was induced uneventfully with Alfathesin $2.5 \mathrm{ml}$ (36 microlitres per kilogram) intravenously over two minutes. The trachea was

Robert Hudson, M.D. and C.T. Ethans, M.D., Department of Anaesthesia, University of Manitoba.

Send Reprint requests to: Dr. C.T. Ethans, Department of Anesthesia, Health Sciences Centre A709, 700 William Avenue, Winnipeg, Manitoba. R3E 0Z3. not intubated and anaesthesia was maintained with enflurane two per cent delivered in oxygen six litres per minute through a circle absorber system. After eight minutes, the patient began to have intermittent myoclonic activity. This consisted of violent flexion of the extremities and contraction of trunk and facial muscles. There were no tonic-clonic movements or other signs of a grand mal seizure. Enflurane was discontinued and anaesthesia was maintained with nitrous oxide four litres per minute and oxygen four litres per minute. The patient maintained adequate ventilation and his blood pressure was $115 / 75-120 / 80 \mathrm{mmHg}$ with heart rate $75-80$ per minute throughout the anaesthetic.

The myoclonic activity subsided over the next three minutes. Since both Alfathesin and enflurane can cause CNS excitation, it was unclear whether the myoclonic activity was due to only one of the drugs or whether it was due to the combination of these agents. Because the possibility of an interaction between enflurane and Alfathesin should decrease with metabolism of the steroid, enflurane two per cent was added several minutes after the termination of seizurelike activity. This caused renewed myoclonus within three minutes. Enflurane was discontinued and halothane was added to the fresh gas flow. The procedure was completed with no further problems.

The patient has made an uneventful recovery with no neurologic sequelae. He was reinterviewed post-operatively and denied a personal or family history of epilepsy and any drug use or abuse. An interview with his mother revealed that he had a febrile convulsion at eight months of age associated with an upper respira- 
tory infection and hot summer weather. He was not given maintenance anticonvulsant medication at that time and he remained free of seizures.

An electroencephalogram done one week post-operatively was normal, including studies during photic stimulation and hyperventilation.

\section{Discussion}

Alfathesin induces anaesthesia rapidly and smoothly if a dose of 50 microlitres per kilogram or less is given slowly ${ }^{3}$ as was the case in this patient. Doses of 50-60 microlitres per kilogram given intravenously over 10 to 15 seconds have produced seizures in patients with and without demonstrated epileptic foci. ${ }^{2,4}$

Enflurane is also known to cause central nervous system excitation. This is usually associated with arterial enflurane concentrations of three volumes per cent or greater, ${ }^{6.7}$ and is aggravated by hypocapnia. ${ }^{5,6}$ The arterial enflurane concentration in our patient could not have exceeded two volumes per cent. Unfortunately, arterial $\mathrm{PCO}_{2}$ and $\mathrm{pH}$ were not measured in this patient, although he was not hyperventilating clinically and this would be unlikely during enflurane anaesthesia with spontaneous ventilation deep enough to abolish any haemodynamic response to surgical stimulation.

In summary, Alfathesin and enflurane in doses lower than those previously associated with excitatory side effects were given to a patient without demonstrable neurological disease who subsequently developed gross myoclonic activity.
Since both Alfathesin and enflurane have central nervous system excitatory properties, it is possible that these drugs could interact in an additive or synergistic fashion to produce seizures or myoclonus.

It is suggested that this combination of drugs should be avoided, particularly in patients with known convulsive disorders.

\section{ACKNOWLEDGEMENT}

We wish to thank Dr. D.B. Craig for advice in preparation of the manuscript.

\section{References}

1. SteEn, P.A. \& Michenfelder, J.D. Neurotoxicity of anesthetics. Anesthesiology 50:437-453 (1979).

2. ReEs, L.T. Convulsions immediately following althesin. Anaesthesia 30:54-55 (1975).

3. Samuel, I.O. \& DundeE, J.W. Clinical studies of induction agents XL11: Influence of injection rate and dosage on the induction complications with althesin. Br. J. Anaesthesia 45: 1215-1216 (1973).

4. UPPINGTON, J. Epileptiform convulsion with althesin. Anaesthesia 28: 546-550 (1973).

5. Joas, T.A., Stevens, W.C. \& Eger, E.I. Electroencephalographic seizure activity in dogs during anaesthesia. Br. J. Anaesthesia 43: 739-745 (1971).

6. Lebowitz, M.H., ButTT, C.D. \& Dillon, J.B. Enflurane-induced central nervous system excitation and its relation to carbon dioxide tension. Anesth. Analg. 51: 355-363 (1972).

7. BART, A.J., HOM, J. \& Linde, H.W. Changes in power spectra of electro-encephalograms during anesthesia with fluroxene, methoxyffurane and ethrane. Anesth. Analg. 50: 53-63 (1971).

\section{RÉSUMÉ}

Dans cette observation, les auteurs font la description des symptômes d'excitation du système nerveux central survenus après l'administration d'alfatésine et d'enflurane à des doses inférieures à celles qu'on associait jusque là à ce genre d'incident. Ils expriment l'opinion qu'il pourrait $y$ avoir une interaction entre ces deux médicaments qui aurait pour effet d'augmenter l'incidence des crises convulsives. 